\title{
POLÍTICAS, FORMAÇÃO DOCENTE E PRÁTICAS PEDAGÓGICAS: REFLEXÕES ACERCA DE UMA EDUCAÇÃO INFANTIL INCLUSIVA
}

\author{
POLÍTICAS, FORMACIÓN DOCENTE Y PRÁCTICAS PEDAGÓGICAS: \\ REFLEXIONES ACERCA DE UNA EDUCACIÓN INFANTIL INCLUSIVA
}

\section{POLICIES, TEACHER TRAINING AND PEDAGOGICAL PRACTICES: REFLECTIONS ON INCLUSIVE CHILDHOOD EDUCATION}

\author{
Cleriston Izidro dos $\mathrm{ANJOS}^{1}$ \\ Shirley SILVA ${ }^{2}$ \\ Cleber Nelson de Oliveira SILVA ${ }^{3}$
}

RESUMO: Este artigo analisa a tríade - política educacional, formação docente e práticas pedagógicas - compreendendo-os como elementos balizados pelos contornos das políticas sociais e que se entrelaçam diretamente na construção de uma educação inclusiva. Considera, ainda, as implicações deste processo para os cotidianos educacionais, particularmente os da Educação Infantil, apontando para elementos a partir da discussão das diferenças humanas, contribuindo para uma leitura mais aprofundada e analítica da questão. Dentre os princípios que subsidiaram o percurso metodológico, consideramos inexorável discutir a relação cuidareducar como fator para uma ação integrada das políticas sociais, sendo imprescindível pensar a inclusão como política de garantia do direito à educação para todos, portanto, como dever do Estado e dos respectivos sistemas de ensino.

PALAVRAS-CHAVE: Educação infantil. Inclusão. Diferenças. Políticas sociais.

RESUMEN: este artículo analiza la tríada - política educativa, formación docente y prácticas pedagógicas - comprendiendo como elementos balizados por los contornos de las políticas sociales y que se entrelazan directamente en la construcción de una educación inclusiva. También considera las implicaciones de este proceso para los quotidianos educativos, particularmente los de la educación de la primera infancia, señalando los elementos de la discusión de las diferencias humanas, contribuyendo a una lectura más profunda y más analítica de Pregunta. Entre los principios que subvencionan la vía metodológica, consideramos inexorable debatir la relación cuidado-educar como un factor para una acción integrada de las políticas sociales, y es esencial considerar la inclusión

${ }^{1}$ Centro de Educação da Universidade Federal de Alagoas (CEDU/UFAL), Maceió - AL - Brasil. Professor Adjunto Doutor no Setor de Estudos de Educação Infantil. ORCID: <https://orcid.org/0000-0003-1040-4909>. E-mail: cianjos@yahoo.com.br

${ }^{2}$ Faculdade de Educação da Universidade de São Paulo (FEUSP), São Paulo - SP - Brasil. Professora Doutora no Departamento de Administração Escolar e Economia da Educação. ORCID: <https://orcid.org/0000-00029224-4998>. E-mail: shirley.feusp@usp.br

${ }^{3}$ Instituição de Educação Infantil da Secretaria Municipal de Educação de São Paulo (IEISMESP), São Paulo SP - Brasil. Diretor. Mestre em Educação pelo Programa de Pós-Graduação em Educação da FEUSP. ORCID: <https://orcid.org/0000-0002-0397-8050>. E-mail: cleber.nelson.silva@ usp.br 
como una política de garantizar el derecho a La educación para todos, por lo tanto, como un deber del estado y sus sistemas educativos.

PALABRAS CLAVE: Educación de la primera infancia. Inserción. Diferencias. Políticas sociales.

ABSTRACT: This article analyses the triad educational policies, teacher training and pedagogical practices as elements inscribed within the limits of social policies that intertwine directly in the construction of inclusive education. It also considers the implications of this process in school life, particularly in childhood education, revealing elements from the perspective of human differences, thus contributing to a more in-depth and analytical interpretation of the issue. Among the principles that support the methodological framework, we rigorously discuss the care-educate relationship as a factor for promoting integrated social policies. Moreover, it is imperative to conceive of inclusion as a policy to guarantee the right to education for all and, therefore, a duty of the State and the respective education systems.

KEYWORDS: Childhood education. Inclusion. Differences. Social policies.

\section{Introdução}

Dentre as políticas sociais, o direito à educação tem se configurado como a principal área na superação das desigualdades sociais e dos processos de exclusão daí decorrentes. Nesse sentido, a afirmação de políticas educacionais inclusivas se apresenta não apenas como garantia da efetivação do direito à educação e da escolarização aos excluídos, mas também, e principalmente, pelo seu potencial em minimizar tais desigualdades.

As políticas sociais, dentre elas a política educacional, são atravessadas por um conjunto de fatores advindos de conjunturas políticas, sociais e econômicas que imprimem um desenho na própria compreensão e implementação dessas políticas, permitindo que sejam mais ou menos permeáveis no cotidiano social e educacional. Essa impressão, por sua vez, delimita-se tanto no campo da macro como no da micropolítica. Dessa forma, se no campo macro o discurso político afirma-se como inclusivo, uma série de ações de implementação precisa ser planejada e efetivada para que se solidifique, para além de uma afirmação de princípios. Por outro lado, no campo da micropolítica, lócus da operacionalização, outros atravessamentos produzidos nos cotidianos educacionais se colocam em ressonância com os processos sociais ampliados, e inclusive como repercussão das ações da macropolítica. Nessa teia, situam-se as relações entre Educação Infantil e inclusão. 
Se por um lado, a Educação Infantil, primeira etapa da educação básica, tem obtido avanços legais significativos enquanto política social, na perspectiva de assegurar o direito da criança e da família a um trabalho formativo de qualidade, por outro, ainda é preciso avançar na luta pelo atendimento à infância de modo integrado, emancipatório e respeitoso para com todas as crianças.

A inclusão, entendida como denominador do direito à diferença, do direito à igualdade e do direito a outros tempos e espaços, coloca-se constantemente como elemento tensionador das múltiplas práticas excludentes, quiçá segregadoras, e discriminatórias, expoentes do combate aos preconceitos. Nessa perspectiva, o princípio da educação inclusiva vem se firmando como norteador das políticas educacionais desde o início dos anos de 1990, seja na discussão do direito à educação para todos, criticando qualquer restrição em função de uma condição de deficiência, por exemplo, como na visibilidade da situação de exclusão e segregação à qual eram submetidos do/no contexto educacional aqueles aí demarcados. $\mathrm{O}$ fato é que essa discussão centralizou-se, sobretudo, no ensino fundamental, deixando, assim, de ser pautada na educação para primeira infância, promovendo uma lacuna histórica nas contribuições de instituições educacionais mais inclusivas.

Por meio deste artigo, intencionamos apontar elementos que permitam subsidiar uma análise entrelaçada e implicada entre a política educacional, a formação docente e as práticas pedagógicas no contexto da Educação Infantil, com recorte na discussão sobre inclusão, considerando ainda que essa tríade - políticas, formação docente e práticas - compõe critérios para a avaliação da própria política. Esses três eixos constituem, por si, campos de análises, estudos, pesquisas e debates acadêmicos e teóricos extremamente aprofundados.

Silva (2018) aponta para a importância de nos debruçarmos sobre a temática. Em seu estudo, que se desenvolve a partir da díade Educação Infantil e as crianças com deficiência, argumenta que o não atendimento pela política educacional brasileira desta parcela da população tem como consequência fazê-la habitar no que nomeou de "não-lugar" ou “invisibilidade". Nesse vazio de atendimento, segundo o autor, pode-se acrescentar a baixíssima produção acadêmica que correlacione os bebês e crianças pequenas às situações de deficiências. Em revisão bibliográfica realizada para sua pesquisa, constatou que apenas 3\% do total de trabalhos publicados, que se relacionavam de alguma forma com a temática, tratavam de situações de inclusão, ou produção de desigualdades nas políticas de educação para crianças de 0 a 5 anos de idade. 
Um conjunto significativo de trabalhos teóricos e acadêmicos centra-se no viés dos cotidianos educacionais, assim como outro conjunto foca em discutir a infância, seja por meio de uma análise mais ampla, seja pela interlocução com outros marcadores sociais, como raça, gênero, classe social e idade. Inferimos que esses marcadores se inserem, nessas produções, enquanto construções culturais, todavia as deficiências ainda se mantêm sob uma visão biomédica, o que talvez subsidie a não incidência e a não incorporação dessa situação, das deficiências, em estudos sobre a infância sob outras perspectivas, incluindo as pesquisas em educação.

Todos esses fatores têm especificidades que requerem estudos direcionados, mas, certamente, dada a conjuntura socioeconômica do país, as desigualdades vividas por crianças vinculadas a esses marcadores se potencializam quando associadas à pobreza, o que aponta para um cenário dramático de vulnerabilidade e situações de risco, sendo que "a escola acaba por tornar-se o único ponto de apoio dentro do Sistema de Garantias acessível para este público" (SANTOS; FELIPE, 2017, p. 17).

Compreendemos, utilizando expressão de Rosemberg (2012), que se faz necessária uma "vigilância intensa" na produção de textos acadêmicos e governamentais acerca da Educação Infantil, atrelando-a à educação inclusiva. Afinal, o que dizem? A que se referem? Vigilância, pois, conforme afirma Madeira (2004, p. 29), a retórica social tem tomado o conceito de escola inclusiva "para ocultar a desigualdade estrutural que se traduz em desigualdades".

Dessa forma, o exercício aqui proposto é o de, baseado em Veiga-Neto (2012, p. 278), ir aos porões, para que "tenhamos sempre em mente as raízes sobre as quais se sustentam o piso intermediário - da nossa vida cotidiana - e o sótão - pelo qual (nos) projetamos para diante e para o futuro", no sentido de assinalar questões que formam um pano de fundo sobre o qual as políticas públicas, consequentemente a educacional, formulam-se e dão corpo e vida aos inúmeros cotidianos educacionais no país.

Para tal, o artigo está estruturado em três segmentos: (i) da (in)visibilidade política das diferenças humanas; (ii) da contextualização da Educação Infantil e das políticas de inclusão no Brasil; e (iii) dos desdobramentos, da discussão anterior, na e para a formação de professores e para as práticas pedagógicas.

\section{A (in)visibilidade política das diferenças humanas}


As políticas de caráter social, em especial a educação, avançaram substancialmente ao longo da história, tendo destaque o período compreendido entre o século XX e XXI. Os avanços tecnológicos promovidos pela humanidade e a disposição humana em explorar afora dos limites geográficos dos territórios nacionais trouxeram à cena as diferenças e o multiculturalismo, como dispositivos estruturantes e transversais na compreensão dos modos de produção econômica e da cultura das sociedades, além da consolidação dos princípios dos direitos humanos e sociais.

No entanto, ainda que do avanço de tais conceitos derive a concepção de igualdade entre as diferenças, as questões impostas pela "invisibilidade" e do "não- lugar" (SILVA, 2018), ocupado por grupos de pessoas, majoritariamente marcados pelas diferenças como anormalidades, resultantes de um padrão estabelecido de homem, nunca foram tão presentes.

A modernidade e a ciência, aí estruturadas, foram decisivas na construção de uma determinada compreensão e de um processo classificatório das diferenças humanas que perduram até os tempos atuais nas sociedades ocidentais. Se por um lado, permitiu a produção de novos conhecimentos, os mesmos, conforme Canguilhem (1990), ultrapassaram o caráter descritivo e amalgamaram o caráter valorativo. Esse processo subsidiou, também, um conjunto de teorias que trouxe, para o centro de seus estudos, a vinculação com as desigualdades sociais. O trato com a questão social na modernidade, segundo Castel (1998), produziu processos de institucionalização sustentados na lógica do segregar para melhor atender as especificidades, ainda que fossem derivadas de demandas distintas, como prisões, asilos ou manicômios. Interfaces que se articulam e se estruturam como dispositivos na definição de políticas, reiterando processos de exclusões e desigualdades. Se por um lado, há a produção de um conjunto de ações para atender as diferenças, com processos de institucionalização da atenção, na lógica acima descrita, por outro, há um verdadeiro processo de apagamento, de tornar invisível, os direitos desses grupos.

Assim, o problema da relação das sociedades com as diferenças individuais pode também ser analisado criticamente como expressão e reprodução de assimetrias entre os que definem e os que são definidos como "diferentes" (MADEIRA, 2004, p. 16).

Sob as sombras dessas idiossincrasias que constituíram nossas sociedades, observamos que discursos que defendem a homogeneidade, apropriando-se equivocadamente da ideia de garantia de direitos para todos, continuam presentes no meio educacional. Anjos e Santos (2016), ao analisarem a Base Nacional Comum Curricular, recentemente aprovada pelo 
governo brasileiro, constatam que o texto mantém e reforça as contrariedades do silenciamento da diversidade e da diferença no ambiente educacional. Essas contradições que se apresentam no contexto da macropolítica, como é o caso da Base, e que colidem com princípios de documentos internacionais, como a Declaração Universal dos Direitos Humanos (1948), a Declaração dos Direitos das Crianças (1959), a Declaração Mundial sobre Educação para Todos: satisfação das necessidades básicas de aprendizagem (1990) ou mais recentemente a Convenção Internacional sobre os Direitos das Pessoas com Deficiência (2006), referendam os discursos de padronização humana e de normalização dos indivíduos, reverberando nas mais diversas instituições sociais.

Nesse sentido, na micropolítica de cada instituição de Educação Infantil, as crianças pequenas e com deficiência lidam com distintas formas de desigualdades e suas associações raça, gênero, classe social e idade -, sofrendo discriminação múltipla. Dhanda (2008) assinala a fundamental importância do reconhecimento dessa situação, pois se trata de entender a complexidade vivida por essas crianças, consequentemente, por suas famílias.

No Relatório de 2008 do Unicef, sobre a situação da infância brasileira, afirma-se que as crianças são

[...] especialmente vulneráveis às violações de direitos, à pobreza e à iniquiidade no País. As crianças negras, por exemplo, têm quase $70 \%$ mais chance de viver na pobreza do que as brancas; o mesmo pode ser observado para as crianças que vivem em áreas rurais (UNICEF, 2008, p. 9).

Skliar (2010), ao analisar o Relatório sobre o Direito à Educação, do Conselho de Direitos Humanos da Organização das Nações Unidas, especificamente sobre o direito à educação de pessoas com deficiência, apresenta uma análise contundente dos paradoxos acerca do cenário na América Latina.

[...] ¿cuantas personas con discapacidad podrian estar en el sistema educativo y no lo estan?, ¿donde están esos ninos, esas ninas, esos jovenes con discapacidad que no estan en ninguna institucion conocida?, ¿cuántas personas con discapacidad están en el sistema educativo? [...] ¿en qué medida ha habido una deserción de esta población al no encontrar singularidades pedagógicas adecuadas para ellos en las instituciones comunes, no especiales?

[...] una falta de información que preanuncia un devinir histórico y una dimensión ética del todo particulares: como si hubiera una población, en este caso la población con discapacidad, que preocupa poco y nada, que preocupa poco inclusive hasta el punto de no saber quiénes son, no saber dónde están, no saber qué les pasa, qué necesitan, qué quieren, cómo sería posible garantizar sus derechos más básicos (SKLIAR, 2010, p. 154). 


\section{Contextualizando a Educação Infantil e as políticas de inclusão no Brasil}

A partir da segunda metade do século XX, a Educação Infantil como direito da criança e da família teve avanços em documentos legais que a asseguram como dever do Estado. No Brasil, segundo a Lei de Diretrizes e Bases da Educação Nacional nº 9394 (BRASIL, 1996), artigo 29, a Educação Infantil compreende creches e pré-escolas, sendo responsável pelo "desenvolvimento integral da criança de até cinco anos de idade em seus aspectos físico, psicológico, intelectual e social, complementando a ação da família e da comunidade" (BRASIL, 1996). Partindo do princípio dessa ação colaborativa da Educação Infantil que visa ao desenvolvimento integral da criança, pensar nas questões da infância implica em acolher os diversos contextos e cotidianos educacionais que estão imbricados a um conjunto de experiências que tenha o brincar e as interações como eixos do currículo e que deve compartilhar as indissociáveis tarefas entre o cuidar e o educar.

Conforme o Parecer $n^{\circ} 20$ do Conselho Nacional de Educação, "um novo paradigma do atendimento à infância - iniciado em 1959 com a Declaração Universal dos Direitos da Criança e do Adolescente -" (BRASIL, 2009), incorporado pela Constituição Federal de 1988 (CF/88) e pelo Estatuto da Criança e do Adolescente de 1990, incidiu na "transição do entendimento da creche e pré-escola como um favor aos socialmente menos favorecidos para a compreensão desses espaços como um direito de todas as crianças à educação, independentemente de seu grupo social” (BRASIL, 2009). Além disso, na superação da visão que cindia o educar e o cuidar, sendo o "cuidar como atividade meramente ligada ao corpo e destinada às crianças mais pobres, e o educar como experiência de promoção intelectual reservada aos filhos dos grupos socialmente privilegiados" (BRASIL, 2009). Tal concepção teve claramente influência na política que se caracterizava "pela ausência de investimento público e pela não profissionalização da área” (BRASIL, 2009).

As creches e pré-escolas têm que ser consideradas pelos sistemas de ensino como demandantes, a partir de suas especificidades, de lógicas próprias de atenção e organização da relação cuidar-educar.

Cuidar exige colocar-se em escuta às necessidades, aos desejos e inquietações, supõe encorajar e conter ações no coletivo, solicita apoiar a criança em seus devaneios e desafios, requer interpretação do sentido singular de suas conquistas no grupo, implica também aceitar a lógica das crianças em suas opções e tentativas de explorar movimentos no mundo (BRASIL, 2009a, p. 68-69). 
A trajetória histórica da Educação Infantil brasileira tem sido objeto de discussão de vários autores, dentre os quais Kuhlmann Jr. (1998) e Kramer (1995). Para a presente reflexão, é relevante recuperar o fato de que nessa trajetória a Educação Infantil carrega traços de assistencialismo, no caso das creches, e traços da escolarização tradicional herdada do ensino fundamental, no caso das pré-escolas (ROSEMBERG, 2012).

Ao contrário do que vimos, o Estado deve promover esforços na direção de integrar as políticas das áreas da assistência social, da saúde e da educação nessa etapa da educação básica, em uma perspectiva que vise contribuir para a emancipação das crianças e de suas famílias. Em uma discussão correlata, Santos e Felipe (2017) afirmam que com "suas perspectivas e enfoques diferentes" outros campos de conhecimento têm

[...] auxiliado a compreender melhor a criança e elaborar diretrizes para dar conta do complexo universo infantil, principalmente porque evidenciam a criança como ser em desenvolvimento, por isso passivo de cuidados específicos, mas potente e capaz, por isso demandante de educação sistemática e cuidadosamente pensada e (re)organizada com vistas a atendêla em sua integralidade a cada tempo, espaço e contexto onde estiver inserida (SANTOS; FELIPE, 2017, p. 20 - grifo dos autores).

Ao mesmo tempo, o Estado brasileiro já detém elementos que mostram a necessária e urgente articulação entre tais áreas das políticas sociais para uma atenção integral à infância. Análises dos assistidos pelo Benefício de Prestação Continuada (BPC) ${ }^{4}$ demonstraram que, em 2012, 30\% das crianças e adolescentes das famílias atendidas, em função da situação de deficiência, não frequentavam nenhum espaço educacional. A importância aqui está, justamente, no fato de que os beneficiários do programa se encontram entre a extrema pobreza e a miséria. Tal dado levou à proposição do BPC Escola, ação interministerial na qual o Ministério da Educação deve monitorar as matrículas e realizar busca ativa das crianças e dos jovens com deficiência de famílias beneficiárias do BPC que ainda permanecem fora da escola (BRASIL, 2007), a fim de garanti-los o direito à educação.

Soma-se, a todos esses condicionantes, uma intervenção muito mais contundente do Estado nas políticas de atendimento às crianças em idade pré-escolar em comparação às matrículas nas creches, reforçando uma representação daquela como instituição preparatória para o ensino fundamental. Silva (2018) indica o percentual de atendimento em ambas as instituições, apontando que enquanto as creches brasileiras atendiam somente $24 \%$ da

${ }^{4}$ O BPC é programa do Ministério do Desenvolvimento Social, assegurado pela Constituição Federal de 1988, que garante a transferência de um salário mínimo mensal a idosos com mais de 65 anos, ou para pessoas com deficiência que tenham comprovada sua incapacitação para a vida independente e para o trabalho. 
população de seu público-alvo, a pré-escola tinha uma cobertura de $81 \%$ da população de 4 e 5 anos de idade. Essa discrepância da política se acentua, e também pode ser observada, quando o autor apresenta os dados de atendimento de crianças com alguma deficiência em instituições de Educação Infantil. Enquanto $43 \%$ da população na faixa etária de 0 a 5 anos era atendida, somente $13 \%$ da população na mesma faixa etária que apresentava alguma deficiência tinha matrícula garantida em creches e pré-escolas.

Como vem sendo observado, a efetivação do direito à educação a todas as crianças brasileiras e de suas famílias convive com diversos entraves e paradoxos, que vão desde as questões da democratização do acesso, da qualidade do atendimento, das condições de trabalho dos professores e professoras, da existência da diversidade de equipamentos e de materiais e gestão democrática, até a superação de uma visão adultocêntrica ${ }^{5}$ de mundo, segundo a qual os adultos se consideram aqueles que são autorizados a decidir sobre as questões da vida das crianças sem escutá-las e considerá-las como agentes.

A política educacional alicerçada no princípio inclusivo pode ser compreendida tendo início, basicamente, com a Constituição Federal de 1988, ao garantir o direito à educação para todos. No entanto, a utilização da terminologia é adotada, a partir da Declaração de Salamanca de 1994, especialmente, em documentos de política educacional relacionados à educação especial. Desse processo, do ponto de vista de sua implementação, seja nos sistemas de ensino ou da produção acadêmica, a inclusão passa a ser diretamente correlacionada à educação de pessoas com deficiência e à educação especial. E, de certa maneira, acabou por se traduzir pela garantia de matrícula em salas e escolas comuns, sendo que, em diversos contextos, não foram consideradas as necessidades específicas das crianças.

Contrariamente à expectativa de que a inclusão daria visibilidade aos processos múltiplos de exclusão e exporia as desigualdades produzidas no interior da escola, ao restringir-se à educação especial acabou por estabelecer um novo léxico, o do "aluno da inclusão" e/ou da "escola inclusiva", de forma a reiterar a dualidade que se desejava superar nesta área. As políticas de inclusão demarcam a estruturação das instâncias de coordenação no Ministério da Educação, assim como o conflito a respeito da dualidade entre diversidade e inclusão, demonstrado, por exemplo, na denominação do órgão responsável - Secretaria de Educação Continuada, Alfabetização, Diversidade e Inclusão.

\footnotetext{
5 Pesquisas acerca da infância, a partir da lógica da sociologia da infância, têm indicado a importância de compreendê-la como uma "categoria geracional construída socialmente e as crianças como atores sociais" (OLIVEIRA; ABRAMOVITCH, 2017, p. 292).
} 
Nesse contexto, compreendemos que discutir uma política que se solidifique como inclusiva significa tomar que esta é um indício "[...] da relação das Sociedades com a Diferença ou Diferenças que, em cada momento da sua história, estas reconhecem e sancionam, positiva ou negativamente" (MADEIRA, 2004, p. 16).

A princípio, parece-nos óbvio que, sendo a Educação Infantil um direito de todas as crianças e de suas famílias, a diversidade de crianças e a de infâncias deveria estar contemplada na formulação das políticas e das práticas que nela e dela emanam. No entanto, a presença das discussões sobre inclusão, da Educação Infantil ao ensino superior, já nos aponta para o fato de que este direito não tem sido garantido a muitas pessoas, assim como a atenção da academia para essa discussão se apresenta, ainda, de forma muito reduzida.

Além disso, e de forma paralela, não se pode esquecer que há em curso na implementação das políticas sociais a transferência da responsabilidade do Estado para o setor privado, por meio das parcerias público-privadas, oficializadas na figura público não-estatal criada na reforma do Estado implementada pelo Governo Federal nos anos 1990 (COUTINHO; MORO, 2017).

O modelo de privatização e da terceirização do dever público estruturou basicamente a oferta de educação formal às pessoas com deficiência (SILVA, 2001). Tal modelo também tem sido vastamente utilizado para ampliar a oferta de vagas para a educação infantil em algumas redes de ensino. No entanto, tais instituições devem seguir os princípios da política educacional pública, e nesse sentido é imperativo acompanhar como tem sido os processos de atenção direcionada e integrada às crianças que demandam por tal especificidade.

\section{Desdobramentos na e para as políticas de formação de professores e para as práticas pedagógicas}

Não há dúvida de que a formação de profissionais da educação que prime por uma escola para todos, portanto inclusiva, deva possibilitar a desconstrução do olhar homogeneizante sobre as crianças e as infâncias. Para que "nosso trabalho cotidiano" incorpore "o discurso das diferenças não como desvio, que é o lugar que o diferente tem sido colocado, mas como o mote de nossas práticas e das relações entre as crianças" (ABRAMOWICZ; OLIVEIRA, 2012, p. 63), é preciso que tal formação não se limite em disciplinas voltadas à inclusão, como educação especial ou correlatas, mas da tomada para si, por todas as demais disciplinas - sociologia, psicologia, filosofia, as metodologias e didáticas, os estágios supervisionados - da diferença como eixo norteador, situação que poderá permitir 
a ruptura da dualidade entre aquilo que tem sido intitulado como educação comum e aquela dirigida a quem está no campo da inclusão.

Assim, não basta trocar uma visão biológica para a social e histórica (ABRAMOWICZ; OLIVEIRA, 2012, p. 58), antes é preciso contextualizar as crianças, as infâncias e nos questionarmos a respeito dos modos pelos quais compreendemos as situações de deficiência, para podermos entender as implicações de uma educação inclusiva. Por que tomar as concepções e práticas dos educadores como campo de estudo e da formação profissional é fundamental? Porque a sociedade os "delega o poder de sinalizar, descrever, medir e atribuir significado valorativo a características, desempenhos e interpretações das crianças e jovens com deficiência" (MADEIRA, 2004, p. 16).

Por outro lado, há que se ter um real investimento nos percursos formativos dos docentes, de conhecimentos e aprofundamentos que integrem produções de outras áreas, que considerem a necessidade de abordagens integradas de atenção à criança, por exemplo, as discussões realizadas no interior de cursos como terapia ocupacional e fonoaudiologia podem contribuir com elementos à contextualização dos modos de expressão e interação próprias a essa faixa etária. Deve-se ter claro que não se trata de estipular protocolos e delimitar situações dentro ou fora da normalidade, mas de não desconsiderar que esse é um momento da vida humana em que várias produções e conexões biopsicomotoras se instauram e se desenvolvem. Tal perspectiva não promove um afastamento das pedagogias, pelo contrário, reitera o cuidar-educar que se dá nas instituições de Educação Infantil.

Mesmo diante da sua importância, a formação de professores tem sido um campo de investimentos precários por parte dos governos, seja na formação inicial ou na continuada. Cursos sem aprofundamento, que não permitem ressignificar constantemente a realidade social em que se vive, de se apropriar dos debates teóricos e acadêmicos que tragam o novo, não o modismo, mas que auxiliem nas práticas cotidianas. Consideramos que cursos emergenciais, uma das opções do Ministério da Educação para formação para a inclusão, vão à mão contrária de uma formação sólida.

Há duas questões de extrema complexidade: a primeira trata da formação da docência visando compreender o humano em sua produção histórica, social e política, e aí poder-se-ia compreender a cartografia da desigualdade do país e das múltiplas exclusões, além do atravessamento por dispositivos que são contextualizados em seu tempo, como o advento da tecnologia nos últimos quinze anos. 
A segunda trata da formação que permita a compreensão da diversidade de situações que podem demandar uma atenção direcionada, na medida em que as situações cotidianas se estruturam como dificultadoras da apropriação do conhecimento e que podem, justamente, em movimento contrário aos fins de um espaço educativo, produzir exclusões em seu interior. Ainda, reconhecer a possibilidade de especificidades individuais que se apresentam e que demandam situações alternativas para a apreensão e produção dos conhecimentos. Esse ponto é, talvez, um dos maiores impasses aos quais as políticas de inclusão não têm conseguido dar resposta. Atender as necessidades não significa excluir, mas para tal há que se ter uma docência com formação sólida, que amplie seus conhecimentos teórico-práticos, permitindo lidar com a diversidade que se coloca a uma escola de todos, mas ao mesmo tempo seja capaz de promover sensibilidade para que este profissional, contrariando um modelo homogeneizador e propedêutico de um currículo conservador, possa elaborar questões, como Madeira (2004) aponta,

[...] que problemas "nos" preocupam? o que a criança faz com o que, onde, quando e com quem? o que mais a criança pode saber e fazer para participar mais vezes e durante mais tempo, em contextos de interação com um maior número de pessoas, potencialmente significativas para as suas vidas? quem, como, onde e quando pode ensinar o que ela precisa aprender? que recursos existem ou poderiam ser criados para facilitar esta aprendizagem e melhorar as condições de relacionamento entre todas as pessoas implicadas neste processo educativo e na vida da criança? (MADEIRA, 2004, p. 22)

Esses questionamentos elaborados no exercício da docência, configurados em sua prática, são ferramentas importantes para que se possa traçar caminhos para respostas alicerçadas nos preceitos de uma educação efetivamente inclusiva, que contemple a diversidade de raça, gênero, classe social e idade.

\section{Considerações finais}

A ideia e a necessidade de políticas integradas de atenção à criança pressupõem uma compreensão de que as mesmas são responsabilidade de todas as políticas sociais, e essa compreensão é fundamental para a construção de uma educação que realmente esteja compromissada com as diferenças e a diversidade.

Considerar as especificidades das crianças, a diversidade e a diferença como dimensões fundamentais das práticas de Educação Infantil reforçam a defesa da necessidade 
de repensarmos a política nacional de educação a partir de uma perspectiva inclusiva e integrada a outras áreas de ação social do Estado.

Diante das considerações e apontamentos levantados nesse artigo, alguns elementos podem ser recuperados, que, do nosso ponto de vista, precisam ser constantemente reafirmados, a saber: a imprescindível ação do Estado que privilegie uma formação docente que de fato abarque a necessidade de condução de um trabalho pedagógico que contemple as diferenças e diversidades presentes nas infâncias; políticas sociais que estejam integradas entre si, reconhecendo dessa forma o sujeito, nesse caso a criança, em sua integralidade; o reconhecimento de que no contexto da Educação Infantil processos de inclusão são perpassados pela tríade - políticas, formação docente e práticas -, que compõe critérios para a avaliação da própria política. A inclusão, dessa forma, é um elemento analítico e não descritivo desse processo; ou, quiçá, a escola inclusiva seja, como afirma Madeira (2004, p. 17), “[...] dentro de alguns limites, construída como lugar de tomadas de posição que desestabilizem os mecanismos da reprodução social, precipitando assim a reconstrução e a democratização social”.

\section{REFERÊNCIAS}

ABRAMOWICZ, A.; OLIVEIRA, F. As relações étnico-raciais e a sociologia da infância no Brasil: alguns aportes. In: BENTO, M. A. S. Educação infantil, igualdade racial e diversidade: aspectos políticos, jurídicos, conceituais. São Paulo: Centro de Estudos das Relações de Trabalho e Desigualdades - CEERT, 2012.

ANJOS, C. I.; SANTOS, S. E. As crianças pequenas precisam de uma base nacional comum curricular? À guisa de apresentação. Debates em Educação, Maceió, v. 8, n. 16, p. i-vi, dez. 2016.

BRASIL. Constituição (1988). Constituição da República Federativa do Brasil. Brasília: Senado, 1988.

BRASIL. Lei Federal no 8.069, de 13 de julho de 1990. Dispõe sobre o Estatuto da Criança e do Adolescente e dá outras providências. Diário Oficial da União, Brasília, 16 jul. 1990. p. 13563.

BRASIL. Lei Federal n 9.394, de 20 de dezembro de 1996. Estabelece as Diretrizes e Bases da Educação Nacional. Diário Oficial da União, Brasília, 23 dez. 1996. p. 27833.

BRASIL. Decreto $n^{\circ}$ 6.214, de 26 de setembro de 2007. Regulamenta o benefício de prestação continuada da assistência social devido à pessoa com deficiência e ao idoso e dá outras 
providências. Diário Oficial da União, Brasília, 28 set. 2007. p. 16.

BRASIL. Parecer Conselho Nacional de Educação nº 20, de 9 de dezembro de 2009. Revisão das Diretrizes Curriculares Nacionais para a Educação Infantil. Diário Oficial da União, Brasília, 9 dez. 2009. Seção 1, p. 14.

BRASIL. Práticas Cotidianas na Educação Infantil - Bases para a reflexão sobre as Orientações Curriculares. Projeto de Cooperação Técnica MEC e UFRGS para construção de Orientações Curriculares para a Educação Infantil. Ministério da Educação - Secretaria de Educação Básica e Universidade Federal do Rio Grande do Sul. Brasília, 2009a.

CANGUILHEM, G. O normal e o patológico. Rio de Janeiro: Forense Universitária, 1990.

CASTEL, R. A metamorfose da questão social: uma crônica do salário. São Paulo: Editora Vozes, 1998.

COUTINHO, A. S.; MORO, C. Educação Infantil no cenário brasileiro pós golpe parlamentar: políticas públicas e avaliação. Revista Zero-a-Seis, v. 19, n. 36, p. 349-360, juldez. 2017.

DHANDA, A. Construindo um novo léxico dos direitos humanos: convenção sobre os direitos das pessoas com deficiências. SUR - Revista Internacional de Direitos Humanos, São Paulo, Ano 5, n. 8, jun., 2008.

KRAMER, S. A política do pré-escolar no Brasil: a arte do disfarce. 5. ed. São Paulo: Cortez, 1995.

KUHLMANN JR., M. Infância e educação infantil: uma abordagem histórica. Porto Alegre: Mediação, 1998.

MADEIRA, R. A Educação que se constrói como "EspecialmenteInclusiva". Revista da Educação PUC-Campinas, n. 16, p. 15-31, jun., 2004.

OLIVEIRA, F.; ABRAMOWICZ, A. Políticas Públicas e Direitos das Crianças: uma reflexão a partir da perspectiva étnico-racial. Revista Zero-a-Seis, v. 19, n. 36, p. 290-307, jul./dez., 2017.

ORGANIZAÇÃO DAS NAÇÕES UNIDAS. Declaração Universal dos Direitos Humanos. Paris, 1948.

ORGANIZAÇÃO DAS NAÇÕES UNIDAS. Declaração dos Direitos das Crianças. Nova Iorque: 1959.

ORGANIZAÇÃO DAS NAÇÕES UNIDAS. Convenção sobre os Direitos das Pessoas com Deficiência. Nova Iorque: 2006. 
ROSEMBERG, F. A criança pequena e o direito à creche no contexto dos debates sobre infância e relações raciais. In: BENTO, M. A. S. Educação infantil, igualdade racial e diversidade: aspectos políticos, jurídicos, conceituais. São Paulo: Centro de Estudos das Relações de Trabalho e Desigualdades - CEERT, 2012.

SANTOS, G. F. V.; FELIPE, J. Redes de proteção à infância: Ampliando a noção de cuidado na educação infantil. In: ALBUQUERQUE, S. S.; FELIPE, J.; CORSO, L. V. (Orgs.) Para pensar a educação infantil: políticas, narrativas e cotidiano. Porto Alegre: Editora da UFRGS, 2017.

SILVA, C. N. O. Primeira infância e situações de deficiências: elementos para uma análise do (não) direito à educação. Dissertação (Mestrado em Educação) - Programa de PósGraduação em Educação da Faculdade de Educação, Universidade de São Paulo, São Paulo, 2018 .

SILVA. S. Exclusão do público, inclusão do privado: a terceirização dos serviços na Educação Especial. Anais... REUNIÃO ANUAL DA ANPED, 24, 2001, Caxambú. 2001.

SKLIAR, C. De la razón jurídica hacia una ética peculiar. A Propósito del informe mundial sobre el derecho. Política y Sociedad, v. 47, n. 1, p. 153-164, 2010.

UNESCO. Declaração Mundial sobre Educação para Todos. Satisfação das necessidades básicas de aprendizagem. Jomtien: 1990.

UNESCO. Declaração de Salamanca. Sobre Princípios, Políticas e Práticas na Área das Necessidades Educativas Especiais. Salamanca: 1994.

UNICEF. Situação Mundial da Infância 2008. Caderno Brasil. Brasil (DF), janeiro de 2008. VEIGA-NETO, A. É preciso ir aos porões. Revista Brasileira de Educação, v. 17, n. 50, p. 267-282, maio-ago. 2012.

\section{Como referenciar este artigo}

ANJOS, Cleriston Izidro dos.; SILVA, Shirley.; SILVA, Cléber Nelson de Oliveira. Políticas, formação docente e práticas pedagógicas: reflexões acerca de uma Educação Infantil inclusiva. Revista Ibero-Americana de Estudos em Educação, Araraquara, v. 14, n. esp. 1, p. 641-655, abr., 2019. E-ISSN: 1982-5587. DOI: 10.21723/riaee.v14iesp.1.12196

Submetido em: 06/08/2018

Aprovado em: 21/09/2018 